\title{
Você Treina ou Ensaia? Dicotomias no campo circense e propostas para aprendizagem/criação/performance a partir de elementos do Sistema Laban/Bartenieff
}

\author{
Alex Machado \\ Escola Nacional de Circo Luiz Olimecha - ENCLO, Rio de Janeiro/RJ, Brasil \\ Universidade Federal do Estado do Rio de Janeiro - UNIRIO, Rio de Janeiro/RJ, Brasil \\ E-mail: alextrapezista@yahoo.com.br \\ Nara Keiserman \\ Universidade Federal do Estado do Rio de Janeiro - UNIRIO, Rio de Janeiro/RJ, Brasil \\ E-mail: nara.keiserman@unirio.br
}

\section{Resumo}

O artigo apresenta uma indicação artístico-pedagógica para artistas circenses, que se dá com base nos princípios, conceitos e práticas do Sistema Laban/Bartenieff. A observação de alunos e alunas da Escola Nacional de Circo Luiz Olimecha, no Rio de Janeiro, um microcosmo significativo do circo no Brasil, fez ver a dicotomia, comum no campo circense - e não apenas na Escola, mas também em outros espaços de ensino assim como entre artistas profissionais - que distingue procedimentos técnicos de artísticos. Elementos do Sistema Laban/Bartenieff mostram-se eficientes na solução de tal dicotomia, por oferecerem referenciais que sustentam as duas instâncias, permitindo que se elabore uma metodologia em que são superadas as lacunas entre técnica e arte, treinamento e criação.

Pedagogia circense. Treinamento e Criação. Sistema Laban/Bartenieff.

\section{Abstract}

This article introduces an artistic and pedagogical approach to circus performers, which is based on the principles, concepts and practices of the Laban/Bartenieff System. Students were observed at the National Circus School Luiz Olimecha, in Rio de Janeiro, which is a relevant microcosm of circus in Brazil. The observation showed the recurrent dichotomy in the circus field which is present not only at the School, but also in other teaching spaces and among professional artists: the distinction between technique and artistic procedures. Elements from the Laban/Bartenieff System efficiently address such dichotomy by offering references that support both instances, allowing the elaboration of a methodology in which the gaps between technique and art, training and creation are bridged.

Circus pedagogy. Training and Creation. Laban/Bartenieff System. 


\section{Apresentação}

Na Escola Nacional de Circo Luiz Olimecha (ENCLO), no Rio de Janeiro, entre o final dos anos 1990 e início dos anos 2000, era comum os professores, sendo a maioria circenses itinerantes de lona, dizerem: "já ensaiou seu flic-flac?"1 ou "tem que ensaiar mais essa espacata!"2. Ensaiar, nesse caso, trazia uma perspectiva ao mesmo tempo funcional e expressiva da aprendizagem que visava uma finalidade performativa. Em meados dos anos 2010, muitos alunos e alunas da ENCLO passaram frequentemente a se referir às aulas regulares como treinos, buscando protocolos de rendimento e de avaliação mais próximos das práticas desportivas, como se os momentos de aprendizagem e de criação fossem distintos e, de certo modo, incompatíveis.

Em trabalhos que trazem depoimentos de artistas do circo itinerante (SILVA, 2009) e obras memorialistas como as de Bartholo (1999), nota-se o uso corrente do termo "ensaio", enquanto nos relatos de circenses que atuam presentemente nas ruas de Goiânia (BARRETO, 2018), por exemplo, e no estudo realizado por Santos (2016) com alunos da ENCLO em 2014, a preferência é por "treinar", o que aponta para uma indesejável dicotomia entre espaços, momentos, procedimentos, e, por vezes, em relação aos profissionais que orientarão essas atividades. Importante lembrar a contribuição de Lavers, Leroux e Burtt (2020), que aponta o alto grau de exigência sobre alunos de escolas

\footnotetext{
1 Salto acrobático. Pode ser dividido em duas fases de execução: na primeira, de pé, faz-se um salto para trás arqueando o corpo com os braços estendidos na linha das orelhas até que as mãos toquem no solo, passando pela posição de parada de mãos. Na segunda fase os ombros fazem uma repulsão contra o solo e o corpo assume uma posição de canoa até que os pés aterrissem. Para melhor visualização consultar Bortoleto (2008, p. 31-34) ou link disponível em: https://www.youtube. com/watch?v=ztRIHiso2LM. Acesso em: 01 abr. 2020.

2 Afastamento máximo lateral ou sagital das pernas. Ver Nunomura e Tsukamoto (2009, p. 120) ou link disponível em: https://www.youtube.com/watch?v=174Dj7dfuOk. Acesso em: 01 abr. 2020.
}

de circo profissionalizantes em função de demandas do mercado e também do desenvolvimento que as habilidades circenses tiveram nas últimas décadas.

Historicamente, há uma relação entre as artes circenses e alguns esportes, como a ginástica artística (SOARES, 2005; SILVA, 1996) e muito do repertório de movimentos e metodologias de ensino de tais saberes são assemelhados ou mesmo idênticos. A contribuição entre esses campos vem repercutindo tanto no melhor desempenho dos circenses (LIEVENS, 2015), quanto enriquecendo as práticas da educação física (BORTOLETO; BARRAGÁN; SILVA, 2016).

\section{Ensaiar ou treinar?}

"Ensaio" remete mais prontamente às atividades do campo artístico, enquanto "treino", aos da educação física ou dos esportes. A dicotomia treino versus ensaio emerge de uma perspectiva impregnada entre muitos circenses, que é a dicotomia técnica versus arte. As aulas seriam momentos dedicados ao desenvolvimento das capacidades/ habilidades motoras para aquisição ou aperfeiçoamento de repertório, enquanto os ensaios seriam momentos nos quais métodos e procedimento de criação seriam aplicados na movimentação aprendida e selecionada. Desse modo, essas práticas, que deveriam ser imbricadas, tornam-se antagônicas, fazendo com que o repertório de movimentos circenses não seja, muitas vezes, percebido como portador de expressividade e sentidos per se.

Ensaiar e treinar não são, absolutamente, termos excludentes e trazem aspectos não apenas complementares, mas indissociáveis nesses processos de aprendizagem. É certo que o desenvolvimento consistente das capacidades e habilidades físicas para o desempenho do repertório circense exige uma grande dedicação à exercícios físicos complexos. Os/As circenses precisam de atividades vigorosas e específicas em aulas ou atividades de manutenção para que possam se valer dos movimentos aprendidos de modo eficaz e seguro em seus projetos cênicos, sejam quais 
forem seus objetivos e linguagens performáticas. No entanto, identificar as aulas como treino ou ensaio pode denotar algo mais. Apartar as práticas de técnicas corporais das que incidem sobre a expressividade, colocando-as em momentos e processos de trabalho distintos acaba por trazer dificuldades quando esses alunos e alunas precisam dar conta dos truques $^{3}$ sob influência de elementos da encenação que podem dificultar ou alterar modos usuais de execução. No caso dos/das circenses, o risco iminente e inerente à sua arte é um dos grandes desafios para que consigam conjugar habilidades corporais e expressivas de modo sinergético. Como aponta Almeida:

\section{"[...] quando um acrobata domina muito bem certo exercício, ele pode praticá-lo sem grande preocupação com a cor- reção na execução e, nesses casos, o artista passa a se preocupar com ele- mentos, digamos, mais estéticos da atividade" (ALMEIDA, 2008, p. 282).}

Dicotomizar as práticas circenses entre momentos de técnica e momentos artísticos cria lacunas nos processos tanto de aprendizado quanto de criação e performance, pois o trabalho sobre o repertório não é devidamente acompanhado de procedimentos que promovam a análise e experimentação dos movimentos a partir, e para além, das suas características. Os recursos de expressividade precisam ser treinados tanto quanto, e em consonância, com as técnicas acrobáticas por meio de práticas que auxiliem o desempenho dos truques selecionados em diferentes situações cênicas.

Essa oposição de instâncias a serem coadunadas em cena tende a levar o/a artista a dividir sua atenção e energia entre as necessidades biomecânicas, psíquicas e espaciais que a execução dos movimentos circenses exige e os diversos recursos ne-

3 Truque é o nome pelo qual circenses identificam movimentos típicos do repertório da sua linguagem. Um salto mortal, jogar três aros com uma mão ou realizar uma figura em um trapézio são exemplos de truques. cessários para viabilizar os projetos cênicos em um número. Muitas vezes, essas instâncias não se adequam plenamente, prejudicando o desempenho funcional e/ou expressivo durante a apresentação. Não é raro observar trabalhos em que a narrativa cênica não se sustenta por toda a performance ou quando artistas "alternam as chaves", ora com sua atenção voltada para a execução do repertório, ora para a comunicação de estados e situações: uma personagem, com características marcantes, entra em cena estabelecendo uma atmosfera ou circunstâncias específicas e, subitamente, se dá conta de um trapézio (que sempre esteve ali ou surge como um deus ex maquina). Ao abordá-lo, as qualidades corporais, coreográficas, psíquicas e o enredo apresentados até então somem durante a execução dos truques, reaparecendo talvez pontualmente durante sua atuação ou quiçá ao final de sua sequência acrobática, quando "volta" para a trama. Ou ainda, quando o/a artista consegue manter a coerência entre a narrativa proposta e a movimentação executada por um bom tempo, mas em algum momento um truque específico demanda uma atenção maior ou uma organização corporal diferente da até então estabelecida e que não se adequa à cena, fazendo com que "saia" do personagem ou do universo (corporal ou cênico) criados.

O repertório circense tem uma complexidade de movimentos e um risco objetivo cuja escolha por determinados procedimentos que não se adequem às especificidades da sua performance pode interferir não apenas nos sentidos criados em cena ou na realização dos movimentos, mas provocar erros com consequências fatais. Embora um número seja composto por diversos detalhes e escolhas, e o prazer da plateia esteja, também, em testemunhar a capacidade das/dos artistas de criar e desempenhar essa multiplicidade de habilidades e signos em cena, quando ocorre alguma insegurança ou problema de execução esses detalhes são muitas vezes esquecidos em prol da segurança e/ou do desempenho do truque, abrindo-se mão da narrativa produzida.

Nos processos de elaboração, criação e performance dos alunos e alunas da ENCLO em diferen- 
tes modalidades ${ }^{4}$, alguns aspectos são recorrentes: dificuldade de sustentar elementos narrativos ao longo das performances - sejam números de comunicação mais direta com a plateia, pelo desempenho de personas ou de selfs dos e das artistas (FÉRAL, 2003), sejam em performances com enredos e personagens mais delimitados ou ainda outros modelos de construção como os trazidos por Lavers, Leroux e Burtt (2020); Lehman (2011) e Hamon-Siréjols (2009); falta de metodologias que auxiliem o desempenho do repertório selecionado voltado para os diferentes projetos cênicos (sejam técnicas de criação e performance direcionadas para o fazer circense ou modos de treinamento voltados para as especificidades das encenações almejadas ${ }^{5}$ ); e dificuldade em abordar e/ou justificar os aparelhos circenses e equipamentos ${ }^{6}$ usados em cena de acordo com as situações planejadas. Pode-se pensar que estes seriam problemas previsíveis e mesmo inerentes aos circenses em processos de formação ou profissionais menos experientes. Mas trabalhos como os de Kann (2018), Lievens (2016, 2015), Hamon-Siréjols (2009) apontam para questões semelhantes no âmbito profissional, que indicam se tratar de uma situação presente no campo circense de modo abrangente.

Os dados apresentados até aqui reforçam a

4 Pedagogicamente, as práticas circenses podem ser agrupadas em modalidades (atividades com características similares). Essa classificação sofre variações a depender da instituição, região ou grupo praticante (BORTOLETO, 2008, 2010). O projeto pedagógico da ENCLO, por exemplo, apresenta cinco modalidades: manipulação de objetos; acrobacias aéreas, acrobacias, equilíbrios e outros domínios circenses (MEC, IFRJ, MINC, 2015).

5 Existem diversos artistas, diretores e professores de circo que desenvolvem procedimentos de criação e performance para seus trabalhos, como os apresentados por Lavers, Leroux e Burtt (2020), mas que ainda não foram analisados e/ou publicados, o que dificulta o acesso e, consequente, a prática desses recursos.

6 Aparelhos são, mais especificamente, objetos com ou nos quais artistas se apresentam (claves de malabares, cama-elástica ou uma banquilha de parada de mãos). Equipamentos podem ser, dentre outros materiais e finalidades, elementos como cordas e mosquetões usados na fixação de aparelhos de acrobacias aéreas. ideia de que os processos de aprendizagem, criação e performance não se constituem em etapas distintas e estanques, mas formam um sistema retroalimentador no qual ensaiar um truque ou treinar recursos para a expressividade cênica são conteúdos inerentes e indissociáveis da arte circense. Entender aprendizagem/criação/performance como um sistema imbricado é importante para perceber como as questões que surgem num desses aspectos do processo não se encerram nele, mas repercutem nos demais. Mas se essas questões tendem a se manifestar ao longo desse sistema, uma mesma metodologia poderia ser aplicada em qualquer de suas instâncias a fim de proporcionar possíveis abordagens e resoluções. Assim, interessa buscar princípios e práticas de análise, treinamento, criação e performance que diluam as dicotomias aqui apresentadas.

\section{Sistema Laban/Bartenieff e a pedagogia circense}

A análise a seguir apresenta princípios do Sistema Laban/Bartenieff ${ }^{7}$ (SLB) como proposta metodológica para que treinar e ensaiar, técnica e expressividade não sejam apartados na pedagogia circense. O SLB é um suporte referencial para o trabalho de professores, artistas e diretores adequado enquanto recurso de análise que conduz à autopercepção. É interessante notar que a terminologia la-

\begin{abstract}
7 A Análise Laban do Movimento está em constante processo de investigação em diferentes centros de estudos, cada um oferecendo especificidades na abordagem dos princípios elaborados por Laban e seus discípulos. As importantes contribuições de Irmgard Bartenieff são estudadas e desenvolvidas no Laban/Bartenieff Institute of Movement Analysis (LIMS $尺$ ) que oferece, entre outras atividades, o Certificado de Analista de Movimento (CMA) (Disponível em: https://labaninstitute.org. Acesso em: 05 mai. 2020), enquanto o Trinity Laban Conservatoire of Music and Dances oferece o Choreological Studies Diploma e que, entre outras características, não inclui os estudos de Bartenieff em seu programa (Disponível em: https://www.trinitylaban.ac.uk/. Acesso em: 05 mai. 2020). Para esse estudo, foi utilizado o Sistema Laban/Bartenieff como referencial de base que será, a partir desse trecho, identificado pela sigla SLB.
\end{abstract}


baniana possui semelhanças com noções já utilizadas no circo como peso, fluxo, intenção espacial e formas corporais - ainda que de um modo apenas aproximado das definições propostas pelo Sistema.

Embora amplamente utilizado no teatro e na dança (FERNANDES, 2006), ainda há poucos trabalhos que tratam dos conceitos labanianos no circo. Franca (2012) investigou as contribuições das categorias Esforço e Corpo ${ }^{8}$ com foco nos Bartenieff Fundamentals ${ }^{s m}$ na análise do repertório circense e as relações Corpo-Espaço em seu espetáculo Mundano $^{9}$ (2017). A FEDEC (Féderation Europeénne des Écoles de Cirque Profissionnelles) tem publicações voltadas para professores de circo com propostas de estímulo à criação e análise do movimento com breves menções aos Fatores do Movimento, como em Dumont (2015; 2016). Nunomura, em livro com Tsukamoto (2009) e em artigo com Russel (2002), também aplica os Fatores do Movimento nos fundamentos das ginásticas. Há ainda diversas publicações e trabalhos circenses que claramente têm influências labanianas mas, como aponta Scialom (2017), os conhecimentos produzidos por Laban e seus discípulos foram a tal ponto difundidos que muitas vezes não são mais devidamente creditados.

Neste artigo serão abordados elementos das categorias Esforço e Espaço ${ }^{10}$ aplicados diretamente no sistema aprendizagem/criação/performance

$8 \mathrm{Em}$ trabalhos e publicações mais recentes como os de Franca $(2012,2017)$ aqui apresentados, alguns termos do SLB vêm sendo escritos com a inicial maiúscula para identificar seu uso segundo os conceitos labanianos distinguindo-os de outros usos mais correntes (como a categoria Forma) ou para diferenciar conceitos similares dentro do Sistema (como a categoria Espaço e o Fator do Movimento espaço). De acordo com o período em que as obras em citações foram produzidas, algumas grafias podem apresentar diferenças.

9 Trecho do espetáculo disponível em: https://www.youtube.com/watch?v=epZK587-jns. Acesso em: 20 abr. 2020.

10 Metodologicamente, os conhecimentos labanianos são agrupados em quatro categorias: Corpo (o que se move), Esforço (como o corpo se move), Forma (com quem ou com o quê o corpo se move) e Espaço (onde o corpo se move) (BONFATTI, 2011). circense. No entanto, outros conceitos serão pontualmente mencionados por apresentarem importantes contribuições às análises aqui apresentadas.

Ao referir-se ao SLB, Caschiero afirma que, além de amplo e variado, ele é "teoricamente complexo e poético" (CASCHIERO, 1998, p. 9 apud BONFATTI, 2011, p. 35). Essa afirmação denota como esse sistema apresenta aspectos objetivos e subjetivos, analíticos e sensíveis, oferendo princípios que abarcam modos complementares e indissociáveis de perceber e executar o movimento humano, aplicáveis tanto na vida cotidiana quanto nos processos artísticos.

O SLB traz quatro princípios (ou Grandes Temas, como são chamados) que permeiam todos os conceitos e práticas adequadas ao trabalho sobre o movimento: Interno/ Externo, Estabilidade/Mobilidade, Esforço/Recuperação e Funcionalidade/Expressividade. Esses princípios se baseiam em dualidades complementares, oposições que sustentam e nutrem uma a outra.

Essa forma dual, porém, interrelacionada de pensar e realizar o movimento oferece um caminho metodológico eficiente para abordar as perspectivas antagônicas aqui apresentadas. São conceitos que podem ser utilizados tanto para aquisição e aperfeiçoamento do repertório de movimentos quanto para a elaboração e desempenho artístico de números circenses.

É importante o/a praticante compreender que, para Laban, o movimento surge de atitudes internas identificadas como objetivos, desejos, necessidades ou reações. Essas atitudes podem ser discernidas e classificadas por meio de quatro componentes denominados Fatores do Movimento: fluxo, espaço, peso e tempo (MIRANDA, 1979). Cada um deles possui duas polaridades, com gradações de intensidade entre elas, que favorecem a criação de nuances na realização dos movimentos. Combinações e alternâncias entre os Fatores do Movimento e suas nuances são definidas como qualidades dinâmicas (FERNANDES, 2006). Cada indivíduo apresenta qualidades dinâmicas singulares e recorrentes que caracterizam seus modos de agir e de se expressar, de modo consciente ou inconsciente, configurando seu Ritmo pessoal 
(RENGEL, 2001). Quando combinadas, as qualidades dinâmicas estabelecem Ritmos funcional/expressivamente mais ou menos eficazes e adequados para as situações tanto cotidianas quanto cênicas.

Castilho (2013) aponta como o trabalho sobre o Ritmo e os Fraseados Expressivos ${ }^{11}$ podem auxiliar atores e diretores de teatro, a que se pode acrescentar os circenses: artistas, diretores e professores.

[...] em vez de percorrer intrincados meandros psicológicos na análise de personagem, buscar fazê-lo através do ritmo [...] Da mesma forma, organizar uma cena levando em conta seus acentos principais e secundários, constantes ou irregulares, faz tangível, palpável, aquele aspecto imponderável do teatro que permanece ainda quase sempre sob o domínio da intuição: como prender a atenção do espectador? (CASTILHO, 2013, p. 204).

Ao selecionar que estados, atmosferas ou circunstâncias pretende expressar e instaurar na cena, o/a artista pode analisar de que modo os Fatores do Movimento e suas combinações estão presentes e organizados nessa narrativa. Assim, a partir dessa análise, pode selecionar truques em seu repertório ou criar outros movimentos que possuam qualidades expressivas similares a esse projeto cênico que meIhor comuniquem o que deseja transmitir ao público.

11 "As qualidades expressivas distribuem-se na Frase Expressiva conforme ênfases dadas pelo corpo ou parte do corpo nesta flutuação de esforço e recuperação. Assim, as qualidades formam uma sequência expressiva com momentos mais ou menos intensos. [...] Esta distribuição da qualidade expressiva na frase de movimentos é denominada Fraseado Expressivo" (FERNANDES, 2006, p. 155-156. Grifo da autora). De acordo com os acentos nas intenções do movimento ao longo do Fraseado, ele pode ser Impulsivo, Impactante, Balanço, Acentuado, Constante ou Vibrato.
Uma experiência com alunos iniciantes na ENCLO, que não tinham conhecimento do SLB, foi especialmente relevante. Ao propor a execução do balanço de esquadro ${ }^{12}$ no trapézio fixo, o professor, usando os conceitos do SLB ao longo das aulas, explicou o movimento decupando-o em Frases de Movimento fazendo menções aos conceitos dos Esforços, Organização Corporal, conexões ósseas e Intenções Espaciais, o que resultou, por parte dos alunos e alunas, numa melhor compreensão e execução. Trabalhados em exercícios práticos e, principalmente, por meio da observação dos movimentos executados pelos alunos e alunas da turma, esses conceitos proporcionaram a associação entre as sensações experienciadas e os Esforços, Percursos e Intenções Espaciais analisados como necessários para a realização do movimento.

O balanço de esquadro foi, para fins didáticos, decupado em duas Frases de Movimento ${ }^{13}$ : 1- organização homóloga estabilizando a parte superior e mobilizando a inferior, conexão ísquios-calcanhares para flexão do quadril e contenção do fluxo em peso forte e espaço direto em frente-alta; 2- organização espinhal, ritmo escápulo-umeral, liberação do fluxo em espaço direto até a sensação de peso fraco ${ }^{14} \mathrm{em}$ trás-baixo. O objetivo desse movimento é ganhar impulso para que o corpo seja lançado em determinada

12 Balanço de esquadro (ou balanço de cotovelos) é um movimento de propulsão em aparelhos aéreos. Em suspensão pelas mãos, flexiona-se o quadril trazendo as pernas em ângulo igual ou superior a $90^{\circ} \mathrm{e}$, seguida, libera-se o quadril e as pernas deixando-as unidas indo para trás flexionando levemente os cotovelos. Para melhor visualização consultar: FEDEC (2014).

13 Existem alguns padrões possíveis para a execução desse truque. Stoppel (2010) propõe sua execução partindo e mantendo a posição de canoa, o que altera principalmente a organização corporal e conexões ósseas exigidas.

14 O Fator peso pode estar presente no movimento de forma ativa ou passiva. Ativamente, o movimento é forte ou leve (maior ou menor aplicação de força para sua execução). Passivamente, o movimento é pesado (corpo entregue à gravidade ou abandonado) ou fraco (como no exemplo acima, sendo sustentado pelo espaço sem força aplicada naquele instante). 
direção com menor uso de força. Logo, o trabalho preponderante é o controle e liberação de fluxo e não a aceleração do tempo - como é comumente percebido e praticado por iniciantes. A aceleração e desaceleração percebidas no movimento ocorrem como consequência da liberação e contenção de fluxo. Acentuar o Fator tempo pode alterar as qualidades dinâmicas desse movimento assim como a organização e conexões corporais mais eficientes, prejudicando sua execução. O mesmo ocorre com a aplicação excessiva de força associada ao Fator peso, que pode prejudicar a contenção e, principalmente, a liberação do fluxo nesse movimento. Mas se o aluno ou aluna realiza essas Frases de Movimento com foco nos Percursos e Intenções Espaciais corretas, tende a usar menos força para esta ação, pois o corpo se projeta nas direções espaciais que favorecem sua execução. O balanço de esquadro completo (considerando as duas Frases divididas para melhor análise e aprendizado) possui seu acento correlato ao Fraseado Balanço do SLB, que tem um aumento gradativo de intensidade até o ponto máximo, seguido de uma gradativa diminuição, o que é muito pertinente à sensação experimentada ao executar esse movimento ${ }^{15}$.

Esse modo de analisar e abordar a prática contribuiu para que esses alunos e alunas desenvolvessem um outro modo de compreender as Organizações Corporais e os Esforços mais presentes nesse e em outros truques realizados no trapézio fixo. Exercícios que trabalham esses princípios foram aplicados e resultaram em progressões pedagógicas eficazes para o desenvolvimento das habilidades exigidas, como no exemplo acima relatado. Do mesmo modo, proporcionou a formulação de parâmetros de análise que passaram a auxiliar em correções dos movimentos, pelo acionamento dos Fatores e demais elementos mais pertinentes.

Outro exemplo pode ser visto no processo de criação do número de Sofia Ferrari, Hasta que el

15 Embora Fernandes (2006) ressalte que esse Fraseado não necessariamente se pareça um com movimento de balanço, neste caso, mostrou-se pertinente. atraso nos separe ${ }^{16}$, aluna da ENCLO entre 20152017. O trabalho aqui analisado é referente à sua pesquisa sobre comicidade em aparelhos aéreos. A situação-base criada pela aluna foi a de uma noiva que estava atrasada e ansiosa para a sua cerimônia de casamento e um de seus sapatos estava no alto do tecido, tendo que subir para buscá-lo. A pressa e o foco direcionado em alcançar o sapato remeteu ao Estado Alerta ${ }^{17}$, e movimentos com essas qualidades foram os primeiros a serem explorados.

Sofia já tinha alguns truques com os quais gostaria de montar seu número. A primeira questão era verificar o quão proficiente ela estava na execução desses elementos, a ponto de conseguir acelerá-los sem comprometer sua segurança nem a comunicação da situação proposta. Esse procedimento, embora simples, é fundamental para a seleção de um repertório mais adequado aos objetivos cênicos almejados. A escolha em desempenhar um personagem-tipo com características especificas dentro de um enredo coloca dificuldades extras na performance do repertório circense pois exige, em algum nível, uma coerência entre os elementos propostos com a movimentação realizada e que seja possível sustentar a narrativa por toda a cena, sem o risco de que se "quebre" o jogo firmado com o público.

Assim, foi recomendado que mantivesse apenas os truques que, de fato, dominasse para não se preocupar com seu desempenho e, se necessário, alterar algumas qualidades dinâmicas que melhor apresentassem as intenções e reações adequadas à cena. Costuma ser delicado para circenses abrirem mão de truques que demandaram tanto empenho e tempo para conquistar, que achem interessantes esteticamente ou pela dificuldade que representam (e, por isso, talvez ganhem mais atenção do público). Mas é importante que professores e diretores ave-

16 Disponível em: https://www.youtube.com/watch?v=RbPeCTYM1MY. Acesso em: 28 mai. 2020.

17 Quando dois Fatores se mostram mais presentes na movimentação temos, no SLB, Estados Expressivos que podem ser: Rítmico, Onírico, Estável, Remoto, Móvel e Alerta (FERNANDES, 2006). 
riguem o quanto alunos e alunas (ou mesmo profissionais) estão dispostos em deixar de apresentar um ou outro elemento em benefício da coesão de signos desejados em seus números. Se, mesmo após avaliar e experimentar, esses e essas artistas insistirem em mantê-los, talvez seja mais interessante repensar o projeto ou os processos de criação escolhidos.

Foi possível observar, nos primeiros ensaios ${ }^{18}$, que o fluxo contido estava presente na movimentação de Sofia, o que se notava pelo tônus e controle que seu corpo assumia para tentar atingir o ponto mais alto do aparelho. Também era perceptível que sua performance se aproximava da comicidade pelo modo como mantinha uma relação direta com o espaço, mas alternando constantemente seu foco, ora no sapato e no objetivo de alcançá-lo, ora no encantamento com a proximidade da festa, manifestado por gestos e comentários de uma vaidade jocosa. Sofia passou a experimentar qualidades acentuadas de tempo acelerado e fluxo contido mantendo sua relação direta com o espaço, remetendo ao Impulso Visual ${ }^{19}$. Mas se a cena demandava essas qualidades como base para sua atuação, era preciso encontrar contrapontos para que pudesse se recuperar desses Esforços.

Do seu repertório, Sofia recorreu a elementos com qualidades opostas às até então mais exploradas e que ofereciam momentos de recuperação para ela. Além de movimentos mais lentos, nessas novas sequências seu tônus também ganhava em relaxamento, liberando o fluxo em seu gestual, o que trouxe qualidades dinâmicas que permitiram não apenas uma recuperação funcional, mas expressiva nas suas ações. Essa recuperação expressiva

18 O termo foi utilizado para reafirmar que, mesmo sendo uma aula, essa atividade tinha caráter de treinamento, aprendizagem e criação de modo imbricado.

19 Movimentos orientandos pela combinação de três Fatores do Movimento mais preponderantes são denominados Impulsos de Transformação, que podem ser Apaixonado, Mágico ou Visual. Quando o fluxo não é relevante (sem empenho de emoções por quem se move) temos as Ações Básicas (Flutuar, Socar, Deslizar, Açoitar, Pontuar, Torcer, Espanar e Pressionar) (FERNANDES, 2006). acompanhada de uma maior variedade de gestos e intenções, trouxe elementos de franca comicidade, confirmada pelas reações de seus colegas ao assistirem ou comentarem os ensaios. Essas características começaram a delinear com mais clareza as dinâmicas da cena e o perfil do seu personagem-tipo - ora aflita para se arrumar (apressada, tensa e focada no objeto), ora muito coquete (modo como a aluna gostava de se referir à sua criação), desfrutando o momento (lenta, mais centrada em si e relaxada). A alternância entre essas qualidades estabeleceu os ritmos-base da cena, que passaram a orientar toda a pesquisa de movimentos.

Outros pontos investigados foram os Percursos e Intenções Espaciais. O foco em conseguir chegar ao sapato acentuava ainda mais a verticalidade, já muito característica em números de tecido. Seria interessante, então, construir outros percursos e formas espaciais que trouxessem diferentes linhas e intenções, oferecendo maior diversidade nas relações Corpo-Espaço (MIRANDA, 2008). Se a dimensão vertical orientava até então as Progressões e Intenções Espaciais, a exploração das dimensões sagital e horizontal passou a contribuir na recuperação funcional mas, principalmente, expressiva da cena (tanto no desempenho gestual da aluna quanto na recepção à sua performance observada nos ensaios), compondo um quadro mais amplo de movimentos, formas e trajetórias.

Um dos elementos de comicidade trabalhados foi o conhecido recurso de triangulação com a plateia. A Intenção Espacial trabalhada nas dimensões sagital e horizontal contribuiu nessa investigação pois a conexão com o Espaço oferecia suporte para a comunicação com a plateia e um referencial que estimulava alterações nas qualidades dos movimentos e formas corporais.

Assim, para criar um equilíbrio em relação a excessiva verticalidade, a técnica de triangulação e o uso das dimensões sagital e horizontal passaram a ser exploradas com mais ênfase. $O$ jogo de dinâmicas que se estabeleceu entre direções e intenções resultou positivamente, não apenas na performan- 
ce cômica da aluna, mas também na espacialidade, pela composição de linhas entre o corpo da aluna, o foco na parte mais alta do aparelho e os comentários com os espectadores, instaurando importantes tensões espaciais e quebras no ritmo-base do número. $A$ dimensão vertical ficou, então, marcada pelos Esforços mais acelerados e contidos, enquanto as demais dimensões eram o contraponto de recuperação, com movimentos mais lentos e livres, ambas com uso acentuado do Fator espaço alternado nas dimensões.

\section{Conclusão}

Os casos relatados apresentam contribuições do SLB para o tratamento das perspectivas presentes em práticas circenses que tendem a opor atividades de treinamento e atividades de criação, trazendo consequências no modo como o alunato vivencia o sistema aprendizagem/criação/performance. A exploração dos Grandes Temas Interno/Externo, Estabilidade/Mobilidade, Esforço/Recuperação e, principalmente, Funcionalidade/Expressividade, ofereceram parâmetros que puderam aproximar a dualidade técnica versus arte pois não opõem uma à outra, mas partem de uma abordagem interdependente que pode ser aplicada em quaisquer atividades que realizem.

Se alunos e alunas conhecem e praticam os princípios labanianos em seus processos de aprendizagem, podem utilizar o mesmo referencial na criação e execução de seus números, pois já têm esses conceitos "encorpados" 20 . O SLB pode, então, permear todo o sistema aprendizagem/criação/performance como um método de análise do movimento, possibilitando que, mesmo em exercícios específicos para um treinamento corporal mais objetivo, os/ as praticantes percebam as qualidades dinâmicas presentes nos movimentos trabalhados e vislumbrem seu potencial expressivo. Do mesmo modo,

20 Termo empregado por Regina Miranda (2008). Para Bonfatti, Miranda apresenta a experiência do corpo como "um processo de (re)leitura, atualização, encarnação, geração e fisicalização de conceitos e produção de sentidos" (2011, p. 54). ao aprender um novo truque, podem buscar no Sistema referenciais seguros para a sua compreensão e execução, como, por exemplo, o uso consciente e intencional do Espaço enquanto suporte/estímulo para o movimento. Ou ainda, em seus processos criativos, avaliar que elementos possuem características pertinentes ao projeto cênico, ou quais qualidades dinâmicas devem explorar a fim de alcançarem seus objetivos expressivos, evitando que lidem com procedimentos e técnicas que podem dificultar ou mesmo comprometer significativamente o desenvolvimento e performance de suas propostas.

Importante salientar que o truque circense possui, sempre, potências sensórias e sensíveis, mas o SLB instrumentaliza o/a artista para a análise das qualidades nele presentes e oferece recursos que podem acentuar ou alterar suas características funcionais/expressivas; traz procedimentos e metodologia de investigação e criação de movimentos com uma terminologia e princípios muito próximos das práticas e experiências cinestésicas que vivenciam habitualmente em seus processos de aprendizagem/ criação/performance e podem ser adequados, com inteligência e sensibilidade, de acordo as necessidades de cada artista em seus projetos artísticos.

\section{Referências}

ALMEIDA, Luiz Guilherme Veiga de. Ritual, risco e arte circense. Brasília: Editora Universidade de Brasília, 2008.

BARRETO, Mônica (Lua). Saltimbancos contemporâneos: seu aprendizado, suas escolhas e expectativas. Goiânia: Editora Espaço Acadêmico, 2018.

BARTHOLO, Ruy. Respeitável público: os bastidores do fascinante mundo do circo. Rio de Janeiro: Letras \& Expressões; São Paulo: Elevação, 1999. 
BONFATTI, Adriana Ferreira. Investigação do jogo cênico no corpo do ator em formação através do Sistema Laban/Bartenieff de Análise do Movimento. 2011. Dissertação (Mestrado em Artes Cênicas): Universidade Federal do Estado do Rio de Janeiro, 2011.

BORTOLETO, Marco Antônio Coelho (Org). Introdução à pedagogia das atividades circenses. vols. I e II. Jundiaí: Fontoura, 2008; 2010.

BORTOLETO, Marco Antônio Coelho; BARRAGÁN, Teresa Ontañón; SILVA, Erminia. (Orgs.). Circo: horizontes educativos. Campinas: Autores Associados, 2016.

CASTILHO, Jacyan. Ritmo e dinâmica no espetáculo teatral. São Paulo: Perspectiva; Salvador: PPGAC/ UFBA, 2013.

DUMONT, Agathe. Verticality, weight and gravity. Federation Europeénne des Écoles de Cirque Proféssionnelles (FEDEC). 2015. Disponível em: http:// www.fedec.eu/en/articles/514-verticality-weight-and-gravity. Acesso em: 29 abr. 2020.

From technical movement to artistic gesture. Federation Europeénne des Écoles de Cirque Proféssionnelles (FEDEC). 2016. Disponível em: http:// www.fedec.eu/en/articles/1750-from-technical-movement-to-artistic-gesture. Acesso em: 29 abr. 2020.

FEDEC. Trapézio estático, cordas e tecido. Publicação online, 2014. Disponível em: http://www.fedec.eu/en/articles/408-static-trapeze-rope-and-silks. Acesso em: 30 mai. 2020.

FÉRAL, Josette. Performance and theatricality - the subject demystified. In: AUSLANDER, Philip. (Ed.). Performance: critical concepts in literary and cultural studies. London and New York: Routledge, 2003.

FERNANDES, Ciane. O corpo em movimento: o Sistema Laban/Bartenieff na formação e pesquisa em artes cênicas. São Paulo: Annablume, 2006. FRANCA, Julia Coelho. Aéreo do corpo, acrobacia da vida. Monografia (Especialização Sistema Laban/ Bartenieff). Faculdade Angel Vianna, 2012.

O corpo tetraédrico: um processo de criação labaniano entre dança e circo. Dissertação (Mestrado). Programa de Pós-Graduação em Estudos Contemporâneos das Artes - Universidade Federal Fluminense, 2017.

HAMON-SIRÉJOLS, Christine. Formas teatrais no circo de hoje. In: WALLON, Emmanuel. (Org.). O circo no risco da arte. Belo Horizonte: Autêntica Editora, 2009.

KANN, Sebastian. Third open letter to the circus: who gets to build the future? 2018. Disponível em: https:// thetheatretimes.com/open-letters-circus-3-gets-build-future/. Acesso em: 09 mar. 2020.

LAVERS, Katie; LEROUX, Loius Patrick; BURTT, Jon. Contemporary circus. London and New York: Routledge, 2020.

LEHMANN, Hans-Thies. O teatro pós-dramático. São Paulo: Cosac-Naif, 2011.

LIEVENS, Bauke. First open letter to the circus: the need to redefine. 2015. Disponivel em: https://e-tcetera.be/first-open-letter-to-the-circus-the-need-to-redefine/. Acesso em: 09 mar. 2020.

Second open letter to the circus: the myth called circus. 2016. Disponível em http://sideshow-circusmagazine.com/being-imaging/letter-myth. Acesso em: 09 mar. 2020. propostas para aprendizagem/criação/performance a partir de elementos do Sistema Laban/Bartenieff Revista Cena, Porto Alegre, n 32 p. 171-182 set./dez. 2020 Disponível em: http://seer.ufrgs.br/cena 
MEC; IFRJ; MINC. Projeto do curso técnico subsequente ao ensino médio em arte circense. 2015. Disponível em: http://www.funarte.gov.br/wp-content/ uploads/2019/03/Resolu\%C3\%A7\%C3\%A3o-11-IFRJ-Aprovar-AD-REFERENDUM-Curso-Tecnico-Arte-Circense-completo-1.pdf. Acesso em: 10 jan. 2020. MIRANDA, Regina. O movimento expressivo. Rio de Janeiro: Funarte, 1979.

Corpo-Espaço: aspectos de uma geofilosofia do corpo em movimento. Rio de Janeiro: 7Letras, 2008.

NUNOMURA, Myrian; TSUKAMOTO, Mariana Harumi. (Orgs). Fundamentos das ginásticas. Jundiaí: Fontoura, 2009.

RENGEL, Lenira. Dicionário Laban. 2001. Dissertação (Mestrado em Artes). Universidade Estadual de Campinas, 2001.

RUSSEL, Keith; NUNOMURA, Myrian. Uma alternativa de abordagem da ginástica na escola Revista da Educação Física/UEM. Maringá: v. 13, n. 1, p. 123-127, 1. sem. 2002. Disponível em: https://pdfs. semanticscholar.org/e8be/3f195f560fba5e3e3ac9d34027d8d9736a22.pdf. Acesso em: 26 mai. 2020.

SANTOS, Carlos Alberto dos. Fascínio circense: arte e pedagogia na Escola Nacional de Circo. Belo Horizonte: Editora Rona, 2016.

SCIALOM, Melina. Laban plural: arte do movimento, pesquisa e genealogia da práxis de Rudolf Laban no Brasil. São Paulo: Summus, 2017.

SOARES, Carmen Lucia. Imagens da educação no corpo: estudo a partir da ginástica francesa no sécuIo XIX. Campinas: Autores Associados, 2005.

SILVA, Erminia. Direito e sociedade: o trabalho circense na legislação brasileira na primeira metade do século XX. 1996. Disponível em: https://www.circon- teudo.com/direito-e-sociedade-o-trabalho-circense-na-legislacao-brasileira-na-primeira-metade-do-seculo-xx/. Acesso em: 14 jan. 2020.

. Respeitável público... o circo em cena. Rio de Janeiro: Funarte, 2009.

STOPPEL, Érika. Trapézio fixo - material didático. São Paulo: Funarte, 2010. Disponível em: https:// www.circonteudo.com/livraria/trapezio-fixo/. Acesso em: 30 mai. 2020.

Sites

Hasta que el atraso nos separe. Número de tecido acrobático. Disponível em: https://www.youtube.com/ watch?v=RbPeCTYM1MY. Acesso em 28 mai. 2020.

Laban/Bartenieff Institute of Movement Studies. Disponível em: https://labaninstitute.org/. Acesso em 05 mai. 2020.

Mundano. Trecho do espetáculo. Disponível em: https://www.youtube.com/watch?v=epZK587-jns. Acesso em 20 abr. 2020.

Trinity Laban Conservatoire of Music and Dance. Disponível em: https://www.trinitylaban.ac.uk/. Acesso em: 05 mai. 2020.
Recebido: $15 / 06 / 2020$

Aceito: 29/07/2020 Aprovado para publicação: 17/11/2020 
Este é um artigo de acesso aberto distribuído sob os termos de uma Licença Crea- tive Commons Atribuição 4.0 Internacional. Disponível em: $<$ http://creative commons.org/licenses/by/4.0>.

This is an open-access article distributed under the terms of the Creative Commons Attribution License 4.0 International. Available at: <http://creative commons.org/licenses/by/4.0>.

Ce texte en libre accès est placé sous licence Creative Commons Attribution 4.0 International. Disponible sur: <http://creativecommons.org/licenses/by/4.0>. 